\title{
ВЫСШЕЕ УЧЕБНОЕ ЗАВЕДЕНИЕ КАК ФОРМА КОММУНИКАТИВНОГО ПРОСТРАНСТВА СОЗАВИСИМОЙ ЛИЧНОСТИ
}

\begin{abstract}
Коммуникация рассматривается как сложный процесс, который организует социокультурное пространство. С помощью процессов коммуникации общество создает информационно-коммуникативное пространство, устанавливая границу между коммуникациями и человечеством. Проанализированы различные научные подходы в психологии и социологии относительно понятия «коммуникативное пространство».

Коммуникативное пространство рассматривается как условие социализации молодых поколений; как совокупность условий для осуществления коммуникативных процессов и как совокупность коммуникативных практик (коммуникативная компетентность, коммуникативная креативность, коммуникативные способности и т.д.).

Разновидностью социально-коммуникативного пространства образования в целом является социально-коммуникативное пространство вуза, который формируется поэтапно в процессе социализации индивидов; претерпевает определенные изменения под влиянием социальных институтов семьи, образования и воспитания, а также неформальных отношений в непосредственном микроокружении; в определенной степени зависит от физических и социально-психологических возможностей личности.

Общение созависимых людей содержит много подавленных мыслей, чувств, скрытых мотивов, низкой самооценки и стыда. Кроме этого, коммуникативное пространство строится по принципу «драматического треугольника» С.Карпмана, в котором существуют взаимоотношения между «преследователем» и «жертвой», между «жертвой» и «спасателем». Если бы спасатель и преследователь прекратили общение, то игра в созависимость закончилась бы.

Так как педагогическая профессия относится к группе «помогающих», «спасающих», то феномен созависимости проявляется и в педагогической реальности высшего учебного заведения.
\end{abstract}

Ключевые слова: коммуникация, пространство, коммуникативное пространство, распоряжения.

\section{ВВЕДЕНИЕ}

Логика научного поиска в плоскости исследования коммуникативного пространства приводит нас к определенному выходному конструкту, согласно которому, почти все науки гуманитарного цикла рассматривают коммуникации (как

\footnotetext{
${ }^{1}$ Милюшина Марина, кандидат психологических наук, доцент кафедры социальной работы Днепропетровского национального университета имени О.Гончара, адрес: пр. Гагарина, 72, еmail: milushina@mail.ru
} 
социальный феномен и как процесс) в двух ракурсах: структурном и функциональном. Таким образом, коммуникативные процессы, с одной стороны, обеспечивают приобретение необходимого багажа знаний, умений и навыков, который в значительной мере определяет характеристики личности, позволяющие ей занять место в одной из социальных групп общества. С другой стороны, участие в коммуникативных процессах выступает как часть определенной социальной роли, обусловленной определенным социальным статусом.

Коммуникативное пространство у созависимых лиц характеризуется стремлением полностью контролировать жизнь других, игнорируя удовлетворение собственных потребностей. Важность данной проблемы обусловлена несколькими моментами - с одной стороны, созависимые отношения мешают полноценной жизни человека, лишая его личностной автономии и индивидуальности, психологические границы членов группы не уважаются и регулярно грубо нарушаются, каждая отдельная личность не в состоянии идентифицировать себя, испытывать удовольствие и радость в любви, интимных отношениях, самореализовываться и самовыражаться, с другой стороны, склонность к созависимым отношениям является фактором риска в развитии более тяжелых форм зависимости. Всестороннее изучение этого феномена в контексте коммуникативного пространства объясняет закономерности развития, состояния и влияния личности и открывает осознанное представление о наиболее общих социально-психологические явления в обществе. В частности, не изученными остаются актуальные вопросы, связанные с раскрытием именно психологической сущности феномена созависимости в пространстве высшего учебного заведения.

Созависимость в виде стереотипов поведения и чувствования в цивилизационном процессе культурной традиции, особенно постсоветской, принималась и утверждалась обществом в качестве идеала, пропагандировалась искусством и литературой.

Феномен созависимости занимает существенное место и в педагогической реальности - в структуре взаимодействия учителя и учащегося. Одним из показателей является переживание частичной несвободы субъектов педагогического процесса в своем отношении к деятельности, к себе, некоторой вынужденности заниматься этой работой и в переживании ограничений своей возможности здесь что-то изменить.

Целью исследования заключается в анализе места и роли созависимых отношений в процессе социализации и профессионализации студенческой молодежи высшего учебного заведения как формы коммуникативного пространства.

Как известно, одной из важнейших сторон формирования цивилизованного общества является его структуризация, которая, в свою очередь, невозможна без формирования «правил игры», где каждый гражданин получает свое место в обществе - социальный статус и, соответственно, выполняет ролевые функции, которые отвечают этому статусу.

Само приобретение приличного, по мнению определенных слоев молодежи, статуса является одной из наиболее важных составляющих планов жизненного самоопределения, которые строит молодежь на этапе дотрудовой социализации. 
Украинские ученые - О. Балакирева ${ }^{2}$, Н. Гендина ${ }^{3}$, Н. Панина ${ }^{4}$, В. Чигрин ${ }^{5}$ - и другие исследователи уже с конца 80-х гг. ХХ в. обращали внимание на сложность механизмов жизненного самоопределения молодежи и приобретения ею личностного и социального статуса. Но все они, выделяли такой элемент механизма реализации жизненных планов, как образование, обучение.

По мнению В. Чигрина ${ }^{6}$, среди молодежи первое место в планах жизненного самоопределения занимает цель получения качественного образования. На втором месте - получение престижной работы, которую, как свидетельствуют материалы исследований и данные литературных источников, значительная часть выпускников на момент окончания общеобразовательной школы понимает достаточно размыто.

Вполне понятно, что условием внедрения жизненных планов является приобретение институциализированных знаний, умений и навыков, необходимых для получения такой работы. Это становится возможным только благодаря институту образования, который воспринимается как один из старейших социальных институтов, призванных способствовать восстановлению общества и его перспективных составляющих, как инструмент передачи социального опыта, как специфическая среда социализации личности и т.п. Однако, исходя из научной цели данной статьи, мы будем изучать институт образования и, в частности, такое его звено, как высшие учебные заведения, которые являются специфической формой коммуникативного пространства.

\section{КОНЦЕПЦИИ ВОЗНИКНОВЕНИЯ «КОММУНИКАТИВНОГО ПРОСТРАНСТВА»}

Ж.-Ф. Лиотар рассматривал современное общество как систему дискурсивных практик, определяя его как «постмодерн». При этом, по его мнению, социальность приобретает характер дискурсивной разнородности, в основе которой лежат языковые игры - «минимальные отношения для существования общества».

В работах П. Бурдье общество является совокупностью отношений, которые складываются в разные поля, каждое из которых имеет специфические типы (политика, образование, наука, философия, журналистика и т. д.). Следовательно, коммуникация представляется в виде сложного процесса, который организует социокультурное пространство. С помощью процессов коммуникации общество создает окружающую среду - информационно-коммуникативное пространство,

\footnotetext{
${ }^{2}$ О.М Балакірєва., О. О. Яременко, Проблеми розвитку соиіології молоді на сучасному етапі. Молодь України: стан, проблеми, шляхи розв’язання : зб. наук. праць. - К.: А. Л. Д., 1996, Вип. 5, с. 226-232

${ }^{3}$ Н.И. Гендина, Образование для общества знаний и проблемь формирования информационной культуры личности. Научные и технические библиотеки, 2007, № 3, с. 4048

${ }^{4}$ Н. В. Паніна, Молодь Украӥни: структура цінностей, соиіальне самопочуття та моральнопсихологічний стан за умов тотальної аномії // Соціологія : теорія, методи, маркетинг, 2001, № 1, c.5-26.

${ }_{5}^{5}$ В. О. Чигрин, Сільська молодь: досвід комплексного соиіологічного аналізу: монографія. Мелітополь: ЗІДМУ, ТДАТА, 2006. - с.78.

${ }^{6}$ Там же, с. 93.
} 
устанавливая границу между коммуникациями, с одной стороны, и человечеством с другой.

Следует констатировать, что, исходя из аксиомы, в соответствии с которой социальная реальность во всех ее проявлениях не может рассматриваться вне пространственного контекста, трудно назвать ученого, который не исследовал бы в контексте определенной парадигмы возникновение и сущность понятия «пространство».

Однако в результате разности задач, различий между сегментами социальной реальности до сих пор не утихают споры по поводу того, что есть пространство и из чего оно состоит, а вследствие этого отсутствуют однозначно сформулированное и стойкое его определение.

Именно поэтому перед тем, как приступить к характеристике такой специфической формы пространства, которой является социальнокоммуникативное пространство образования в целом и его разновидность социально-коммуникативное пространство высшего учебного заведения, проанализируем концепции, которые так или иначе касаются свойств разновидностей пространства.

Понятие «пространство» наиболее детально рассматривал П. Бурдье, который отмечал, что весь мир можно представить себе в форме многомерного пространства, построенного по принципами дифференциации и распределения. В основе концепции пространства П. Бурдье лежит его разделение на физическое и социальное, что объясняется утверждением, согласно которому, «социология должна действовать, исходя из того, что человеческие существа являются одновременно биологическими индивидами и социальными агентами. Как тела и биологические индивиды они размещаются так же, как и предметы, - в определенном пространстве (они не имеют физической способности вездесущности, которая позволяла бы им одновременно находиться в нескольких местах) и занимают одно место» ${ }^{7}$. Исходя из этого утверждения, ученый четко разграничивает физическое и социальное пространство, отмечая то, что «физическое пространство определяется по взаимным внешним признакам частей, которые его образуют, тогда как социальное пространство - по взаимоисключениям (или различиям) позиций, его образующих, иными словами, как структура рядополагания социальных позиций».

С одной стороны, подобное разделение является полностью очевидным, однако за такой простотой скрывается достаточно сложная, временами скрытая связь между этими двумя пространствами. К тому же, как доказывает анализ литературных источников разных эпох, обсуждения связи между социальным и физическим пространствами не возникло лишь в настоящий момент, достаточно внимательно ознакомиться с трудами П. Сорокина ${ }^{8}$.

Стоит подчеркнуть, что отмеченные аспекты волновали ученых еще с древних времен. Но осознание этого факта стало складываться лишь во второй половине $\mathrm{XX}$ в., когда произошла революция в характере информационных взаимодействий,

\footnotetext{
${ }^{7}$ Цит. по: П. Бурдье, Социальное пространство и генезис «классов». Вопросы соичиологии, 1992, Т. 1, № 1, c. 35 .

${ }^{8}$ Об этом подробнее см: П.А. Сорокин, Человек. Цивилизация. Общество : пер. с англ. / (общ. ред., сост. и предисл. А.Ю. Согомонов). М.: Политиздат, 1992. - сс.297-302.
} 
придавшая этим действиям глобальный планетарный характер. Сегодня именно информационные взаимодействия, как воплощение действий коммуникативных, превращают каждое событие в глобальный фактор человеческих отношений. Действительно, как коммуникация, так и информация, приобретают фундаментальный характер, который принуждает придавать этим понятиям онтологический статус.

В связи с этим следует согласиться с А. Калмыковим ${ }^{9}$ в том, что точный смысл понятие «информационно-коммуникативное пространство» может иметь только в таких его трактовках, которые построены на моделях, применимость и эффективность которых зависит от конкретных условий и корректности формулировки научно-практических заданий.

Л. Орбан-Лембрик ${ }^{10}$ предлагает рассматривать коммуникативное пространство как социально-психологическую среду, где возможно построение адекватной коммуникативной модели. Речь идет о такой психологической парадигме, в которой можно было бы реализовать формировочно-развивающую, содержательносмысловую, уточняюще-результативную функции коммуникации. Это возможно благодаря учету в общей психологической парадигме соответствующих парадигм информирования (влияния), взаимоинформирования (налаживание механизма обратной связи, создание общего информационного поля), диалога (взаимопонимания). В этой модели должно последовательно воплощаться понимание коммуникатора и реципиента как реальных участников коммуникативного процесса, уникальной индивидуальности, субъектов информации с соответствующим коммуникативным потенциалом.

Тем не менее, наиболее распространенной остается трактовка коммуникативного пространства как физического пространственно-временного универсума, между точками которого возникают обменные информационные отношения и коммуникации. Социокультурная реальность разворачивается в историческом времени и характеризуется совокупностью коммуницирующих объектов ${ }^{11}$.

Но с нашей точки зрения более приемлемым является «инструментальное» понимание информационно-коммуникативного пространства. Суть его состоит в том, что действительность интерпретируется в качестве некоторого множества практик, каждая из которых контролирует определенные фрагменты социальной жизни.

\section{КОММУНИКАТИВНОЕ ПРОСТРАНСТВО ВЫСШЕГО УЧЕБНОГО ЗАВЕДЕНИЯ}

Мы склонны утверждать, что коммуникативное пространство целесообразно трактовать как в широком, так и в узком смысле. Последняя его трактовка применима к отдельным сферам жизнедеятельности общества, определенных его групп (социальных, демографических, поселенческих, образовательных и т. п.).

\footnotetext{
${ }^{9}$ http://jarki.ru/wpress

${ }^{10}$ Л. Е. Орбан-Лембрик, Соцііальна психологія, Либідь, 2004. Кн.1: Соціальна психологія особистості і спілкування, с.444.

${ }^{11} \mathrm{http}: / / j a r k i . r u / w p r e s s$
} 
В нашем случае коммуникативное пространство следует рассматривать как:

1) условие социализации молодого поколения с целью, с одной стороны, их полноценного вхождения в общество, а с другой стороны, с целью реализации планов жизненного самоопределения путем приобретения желаемого стабильного социального статуса;

2) совокупность условий для осуществления коммуникативных процессов, сущность которых определяется понятиями «учеба», «воспитание», «групповое общение» и т.п.;

3) совокупность коммуникативных практик, которые осуществляются в пределах специфических полей, в совокупности составляющих коммуникативное пространство. Вышеупомянутые поля формируются так называемыми агентами поля, своего рода центрами влияния, зарядами ${ }^{12}$. Человек оказывается в поле под воздействием «агентов поля», которые создают информационно коммуникативный образ какого-либо события.

В результате он соответствующим образом меняет свое поведение и сознание. Кроме того, понятие «поле» непосредственно учитывает в своем содержании как пространственную определенность, так и качественную специфику систем, которые его создают, и систем, которые в нем взаимодействуют. Таким образом, коммуникативное пространство представляет собой совокупность полей присвоения знаний и опыта, включающих в себя, во-первых, пространственновременные условия передачи этих знаний, во-вторых, специфическую человеческую среду (студенты, преподаватели, вспомогательный персонал, библиотекари), которая способствует организации и самоорганизации этого процесса.

Следует согласиться с С. Дацюком ${ }^{13}$, который отмечал, что сегодня, анализируя теоретические поиски по проблеме коммуникации, как правило, останавливаются на изложении уже упомянутых нами западных авторов. Тогда как со стороны советской философии в этом направлении велись исследования не менее интересные, достаточно вспомнить М. Бахтина, Ю. Лотмана, М. Мамардашвили. Для нас наибольший интерес представляет именно этот переход от философии знания к теории коммуникации, совершенный в советское время, а не критика коммуникативной недостаточности философии сознания западными теоретиками.

Более того, уместным является синтез подходов Бахтина-Мамардашвили и Ю.Хабермаса, то есть западной теории коммуникации. У М. Бахтина мы можем позаимствовать идею диалога как постоянного общения в культуре и идею скрытого адресата или оппонента в тексте, без которого смысл текста неясен.

У М. Мамардашвили целесообразно взять концепцию соединенности знания, идею пространства превращения, представления о субъекте и содержательный характер коммуникации. У Г. Щедровицкого мы считаем целесообразно позаимствовать идею о коммуникативном характере смысла и содержания. Именно содержательный характер коммуникации является более производительным по отношению к формальному разделению Ю. Хабермасом коммуникации на коммуникационное действие и дискурс.

\footnotetext{
12 Поля описаны Пьером Бурдье в его лекции в Колледж де Франс, прочитанной им на факультете антропологии Лионского Университета 14 ноября 1995 г.

${ }^{13} \mathrm{http}: / /$ xyz.org.ua/discussion/communicative_strategy.html.
} 
Любой текст (язык), по мнению С. Дацюка, только потенциально является коммуникативным действием, но это еще не значит, что он включен в процесс коммуникации. Тут следует говорить о различии послания и сообщения.

Процесс коммуникации указывает, что его коммуникационная середа доступна непосредственно или с помощью специальных средств. Смысл текста должен быть передан через коммуникативное пространство. Это касается внутреннего содержания текста (разговоры). С другой стороны, всякий текст (язык) становится интерсубъективним как только он включается в реальный процесс коммуникации, в реальное пространство превращения (М. Мамардашвили). Этот процесс превращения впервые обнаруживает себя как творческий процесс самого автора, его внутренний диалог, постоянную постановку себя то в позицию автора, то в позицию потенциального читателя (адресата). Собственно потому первичное пространство превращения порождается самим актом творчества, то есть первичным коммуникативным актом. Вторичный коммуникативный акт связан уже с внешней средой текста, которая в таком случае оказывается средой коммуникации. Коммуникативное пространство - внутренний коммуникативный содержательный смысл текста, а среда коммуникации (или коммуникационная среда) - внешняя реальная среда процесса коммуникации, в которую включен текст (язык).

Научный интерес вызывают выводы, приведенные в монографии Т. Ткач «Образовательное пространство личности: психологический аспект» относительно необходимости адаптации студентов к достаточно специфическому коммуникативному пространству высшего учебного заведения, который в отличие от общеобразовательной школы предусматривает существенное увеличение коммуникативных практик.

Опираясь на материал О. Родина ${ }^{14}$, отметим, что коммуникативное пространство имеет ментальную, информационную, а также институциональную структуру, которая определяет определенный тип пространства. В ходе взаимодействия этого пространства с окружающей средой постоянно разрешаются проблемы адаптации, целеполагания, воссоздание социальной структуры и еe интеграция во взаимодействие с окружающей средой.

Всем этим требованиям отвечает коммуникативное пространство учебных заведений, которое:

а) формируется поэтапно в процессе социализации индивидов;

б) испытывает определенные изменения под воздействием социальных институтов семьи, образования и воспитания, а также неформальных отношений, в непосредственном окружении микросреды;

в) в определенной мере зависит от физических и социально-психологических возможностей лица, которое социализируется.

Таким образом, учебные заведения можно считать специфической институционализированной формой коммуникативного пространства, в пределах которого реализуется выработанный человечеством, присущий только ему способ коммуникации - учебно-воспитательный процесс. Его целесообразно рассматривать в первую очередь с психологической точки зрения, как процесс целеустремленного

\footnotetext{
${ }^{14}$ http://www.sarki.ru/studium/publ1/rodin.pdf.
} 
формирования габитуса, который включает в себя учебу и самообучение, воспитание и самовоспитание. Используя возможности учебно-воспитательного процесса, общество хочет подготовить для себя гражданина и специалиста, а каждый молодой человек через преодоление недостатка социального опыта и навыков коммуникативного характера стремится достичь высшего социального и профессионального статуса.

Понятно, что этот процесс является невозможным без наличия системного общения между преподавателями и студентами, между самими студентами в процессе учебы, наконец, без общения студентов с учебником, пособием, дополнительной научной или справочной литературой, то есть, без организации в пределах учебно-воспитательного процесса разветвленной системы непосредственных и опосредствованных социально и профессионально обусловленных коммуникаций.

\section{ПРОЯВЛЕНИЕ ФЕНОМЕНА СОЗАВИСИМОСТИ В ПРОСТРАНСТВЕ ВЫСШЕГО УЧЕБНОГО ЗАВЕДЕНИЯ}

Многие проблемы возникающие у субъектов коммуникативного пространства высшего учебного заведения обусловлены влиянием созависимости, которая является личностной деформацией представителей помогающих профессий (педагогов, медиков, воспитателей, психологов и т.п.).

По нашему мнению, в данный момент существует необходимость в изучении проявления этого феномена среди участников педагогического процесса. Для этого необходимо глубокое изучение проблемы созависимого поведения, так как, несмотря на высокую социальную, научную, а главное практическую значимость проблемы созависимости, до сих пор отсутствуют попытки теоретического обобщения результатов, что не позволяет создать целостную картину формирования и развития созависимости.

Созависимость можно описать как идентификацию себя с Другим или Другими и нарушение собственной психологической территории вследствие размытости ее границ. В норме человек воспринимает внешнее как внешнее: «Я - это я, а ты - это ты» (Ф. Перлз). Внешнее помещается человеком на границу своей территории, и он задается вопросом, а что, собственно, для меня означает эта фигура; т. е. норма это реальная оценка объективного положения дел с точки зрения нужд и интересов индивида $^{15}$. При созависимости фигура включается в собственную психологическую территорию, «присваивается», и оценка ее места и значимости просто не может быть объективной - ведь это оценка себя. Навязчивость мысли «мне необходимо иметь мужчину (женщину, любимого и любящего ребенка)» поддерживается трудностью разотождествления с Другим, поскольку в этом случае возникает ощущение нарушения целостности себя, экзистенциальный вакуум. Сосредоточению на Другом придается такое значение, что в сравнении с ним все остальные потребности и интересы кажутся второстепенными, а жизнь без Другого - однообразной и никчемной.

\footnotetext{
${ }^{15}$ М. Папуш, Психотехника экзистенцииального выбора, 2001, сс.112-119.
} 
Существуют следующие характерологические особенности созависимых личностей, которые включают в себя поведенческие и психодинамические паттерны:

1) строгое отношение к себе и другим вместе со стремление контролировать собственные мысли, чувства и поступки, а также других людей;

2) заниженная самооценка и желание понравиться окружающим;

3) страх критики и острая эмоциональная реакция на нее;

4) чувство вины при необходимости отстаивать себя, «собственные» интересы;

5) неспособность удовлетворять актуальные потребности человека и определить потребности и личностные границы в отношениях.

Для созависимых характерен стойкий страх не оказаться нормальным, ощущение своего отличия от других и неполноценности, часто относимые на счет врожденной, а потому и неизменной предрасположенности. К.Г. Юнг замечал, что «быть нормальным» - высший идеал неудачников; и стремление восстановить ущемленное самолюбие для людей, чьи способности ниже средних, нередко реализуется в отношениях созависимости, поскольку путь к иным достижениям представляется им чрезвычайно трудным. По утверждению К. Хорни, чувствующие себя в невыгодном положении таят необычайно сильное желание иметь все только для себя, не позволять больше никому ни малейшего наслаждения, отнимать все у всех остальных.

Способ отношения человека к другим всегда представляет собой отражение его истинного отношения к себе и определяет его базовые мотивации. Желание созависимых нравиться окружающим и готовность делать все, чтобы этого добиться, сопровождаются боязнью разорвать даже приносящие явный вред отношения и стремлением сглаживать конфликтные ситуации, провоцирующие разрыв. Компульсивное желание контролировать жизнь других сочетается с верой в свою способность контролировать все, в том числе восприятие себя другими через производимое впечатление.

Будучи уверенными, что лучше всех в семье знают, как должны развиваться события и как должны себя вести другие, созависимые пытаются не позволять другим быть самими собой и не давать событиям протекать естественным путем. Манипуляции - угрозы, уговоры, принуждение, советы - призваны камуфлировать происходящее и подчеркивать беспомощность близких и значимость созависимых в глазах окружающих. Неудачные попытки взять под контроль практически неконтролируемые события рассматриваются как поражение и утрата смысла жизни, но не из-за собственных нереалистических и завышенных ожиданий, а вследствие недостатка способностей вообще.

Манипуляции реализуют и желание заботиться о других, спасать других, проистекающее из низкой самооценки созависимой личности. Не веря, что может быть любимым и нужным просто сам по себе, человек вынужден зависеть от Других и пытается заработать их любовь и внимание любыми способами, стать незаменимым. Недостаточность внутренних ресурсов для исполнения желаемой социальной роли - способностей, культуры чувств, ценностного потенциала обусловливает перенапряжение при ее исполнении и приводит к конфликту между этой ролью и Я, так как оценка роли значительно превышает оценку Я. 
В результате созависимый становится перфекционистом, изнуряющим себя непосильным трудом поддержания видимости близких отношений. Не обладая способностью отличить любовь от жалости, такой человек стремится любить тех, кого есть за что пожалеть и есть от чего спасать, и использует сексуальные отношения как средство пожалеть или как плату за жалость, понимание и сочувствие со стороны Другого.

Созависимые не представляют себе жизни наедине с собой, нуждаются в том, чтобы в них нуждались, и для удовлетворения этой потребности часто берут на себя роль мучеников, страдальцев.

Определить, чего хотят другие, и дать им то, чего они хотят, - в этом цель и интересы созависимых, именно поэтому часто их интимными партнерами становятся люди, или полностью подчиняющие себе или, наоборот, требующие постоянного внимания и заботы.

Правда, как говорилось выше, в чем интересы опекаемого - решают сами созависимые.

Роль опекуна разыгрывается иногда с оттенком жертвенности, иногда с чувством собственного превосходства и сознанием честно исполняемого долга, но тем не менее базовые потребности в любви, уважении, значимости, контроле не насыщаются

Итак, неспособность быть одному, страх одиночества; манипулятивные способы получения внимания и любви, подкуп, демонстрация беспомощности, призыв к справедливости, угрозы, шантаж; ненасытность; требование абсолютной любви; постоянная ревность к партнеру; болезненное восприятие отказа и возражений - все это характеристики созависимости.

Образовательная система поддерживает миф о передаче знаний без стремлений студента к его присвоению и спрашивает с преподавателя не за его деятельность, а за результаты деятельности студентов.

Фактически преподаватель (с высоким уровнем созависимости) всю жизнь доказывает, что достоин внимания и ласки, и страх их утраты толкает его к накоплению самоценностей: социального статуса, образования, внешнего вида, оказанных услуг, принесенных жертв и т.д. Живя иллюзией, что когда-нибудь за все это он получит необходимые ему любовь и признательность от своих слушателей, руководства, в то же время преподаватель демонстрацией своей ценности унижает и отталкивает объект любви. Ставя свое Я в центр отношений, он не дает ответа на заботу, воспринимая ее как должное, не насыщаясь ею, обесценивая или не замечая.

Все коммуникативное пространство созависимых, и, в частности, педагогов, подчиняется драматическому треугольнику С.Карпмана, в котором есть три роли: преследователь, спасатель и жертва, усвоенные в детстве. Преподаватель часто выступает в первых двух ролях, когда считает себя лучше, сильнее, умнее, чем другие (студенты) ${ }^{16}$.

Преследователь использует стиль взаимодействия - доминирование и это означает, что он всегда должен быть прав. Методы преподавателя в роли преследователя - запугивание, проповеди, угрозы, обвинения, чтение нравоучительных лекций, проведение допросов и прямые атаки. Спасатель, как

\footnotetext{
${ }^{16} \mathrm{http}: / /$ psygestalt.ru/treugolnik-karpmana/
} 
правило, пытается «задушить» в другом инициативу, чтобы управлять и манипулировать им - «для его же собственного блага», конечно. Спасателям необходимо чувствовать, что их ценят. Нет лучшего способа почувствовать себя важным, чем роль Спасителя.

Чем больше преподаватели спасают, тем меньше ответственности берет на себя студент. Чем меньше ответственности берут студенты на себя, тем больше их спасают, и это нисходящая спираль, которая часто заканчивается катастрофой.

Использование таких ролей в педагогической деятельности автоматически включает слушателей в роль жертвы, в которой они чувствуют себя униженными и рано или поздно начинают мстить, превращаясь в Преследователя (не обязательно это адресовано тому же спасателю или преследователю). В будущем они не могут заботиться о себе, смотрят на Спасателя снизу вверх и говорят: «Ты единственный, кто может мне помочь» и это то, что жаждет услышать любой Спасательпреподаватель

Следует отметить, что на формирование устойчивой роли жертвы, как правило, влияют установки в детстве. Например, если один из родителей не побуждал своих детей к тому, чтобы они приняли на себя соответствующую их возрасту ответственность, поэтому, став взрослыми, они могут чувствовать свою неадекватность в уходе за собой или чувствовать обиду на взрослых, когда не получают помощи.

С нашей точки зрения такое взаимодействие обусловлено субъект-объектными взаимодействиями между всеми участниками педагогического процесса. При этом, студент воспринимается как тот, кто не имеет перспектив подняться до уровня преподавателя и характеризуется более простым набор потребностей. Осознание роли созависимых отношений в коммуникативном пространстве ВУЗа, с нашей точки зрения, тесно связано с реализацией субъект-субъектного типа отношений. Он предполагает создание паритетного участия обучающихся и обучающих в организации совместной деятельности. Это те взаимоотношения, которые формируют так называемые «педагогику сотрудничества», соуправление, «педагогику ненасилия» и должны быть ведущими в практике образовательных учреждений.

\section{ВЫВОДЫ}

Если обобщить понимание высшего учебного заведения, как специфической формы коммуникативного пространства созависимой личности, то можно утверждать, что в этой плоскости он определяется, во-первых, многоуровневостью, а во-вторых, - многофункциональностью.

Следовательно, коммуникации в высшем учебном заведении осуществляются:

а) на уровне общения преподавателей и студентов во время осуществления учебного процесса. Эта форма коммуникации, в свою очередь, выполняет две функции - функцию передачи знаний и умений от преподавателя к студенту, и наоборот - функцию передачи информации относительно степени усвоения полученной информации и способности использовать ее в процессе выполнения учебных заданий от студента к преподавателю. В частности на преподавателя возлагаются качественно новые задания в процессе педагогического взаимодействия со студентами с целью формирования у них культуры 
профессионального общения. Основой успешного педагогического взаимодействия и педагогического влияния является отношение к студенту как к субъекту, а не объекту учебно-воспитательного процесса, то есть становление и развитие субъектсубъектных учебных взаимоотношений и отказ от ролей «спасателя», «преследователя». Коммуникации на этом уровне носят, по большей части формализованный характер;

б) на уровне неформального общения преподавателей и студентов. Этот способ коммуникаций, с одной стороны, призван стимулировать имеющиеся и формировать новые коммуникативные установки студентов, что будет затруднено в роли жертвы, безответственного отношения к своей жизни. Так как по окончании высшего учебного заведения им придется работать в разных коллективах, общаться с людьми, которые имеют более высокие, или низшие статусы, владеют большими или более малыми профессиональными знаниями и умениями. С другой стороны, неформальное общение преподавателей и студентов, безусловно, в пределах этических норм просветительской деятельности, помогает снимать определенное отчуждение, которое могут чувствовать студенты к преподавателям и учебному заведению в целом;

г) достаточно сложной (формальной и неформальной) выглядит коммуникация между студентами. Анализ коммуникативного пространства молодых людей позволяет констатировать, что на субъектов общения коммуникативное пространство влияет не только непосредственно, через общую информацию, которая образовалась в процессе обмена, но и через средства коммуникации (вербальные или невербальные), установленные в конкретной социальнопсихологической среде правила общения, моральные нормы взаимодействия, обычаи, речевые ритуалы. В связи с этим, перспективным является рассмотрение психологических особенностей коммуникации в студенческой среде.

\section{LITERATURA}

[1] Бурдье П. «Социальное пространство и генезис классов». Вопросы социологии, 1992, T. 1, № 1, 17-37.

[2] Балакірєва О.М. Яременко О.О. «Проблеми розвитку соціології молоді на сучасному етапі». Молодь України: стан, проблеми, шляхи розв'язання. К: А.Л.Д., 1999, Вип. $5,226-232$

[3] Гендина Н. И. «Образование для общества знаний и проблемы формирования информационной культуры личности». Научные и технические библиотеки, 2007, № 3, 40-48.

[4] Лиотар Ж.-Ф. Состояние постмодерна. СПб: Алетейя, 1998.

[5] Орбан-Лембрик Л.Е. Соціальна психологія. К: Либідь, 2004.

[6] Паніна Н. В. «Молодь України: структура цінностей, соціальне самопочуття та морально-психологічний стан за умов тотальної аномії». Соціологія: теорія, методи, маркетинг, 2001, № 1, 5-26.

[7] Родин А.В. Коммуникационное пространство: морфология и трансформация. Studium, 2008, T.6, №1, 1-16. http://www.sarki.ru/studium/publ1/rodin.pdf.

[8] Сорокин П.А. Человек. Цивилизация. Общество : пер. с англ. (общ. ред., сост. и предисл. А.Ю. Согомонов). М: Политиздат, 1992.

[9] Ткач Т.В. Освітній простір особистості: психологічний аспект: монографія. К.: Запоріжжя, 2008

[10] http://xyz.org.ua/discussion/communicative_strategy.html 
[11] http://media2050.ru/2011/11/27/56/.

[12] http://jarki.ru/wpress

[13] http://psygestalt.ru/treugolnik-karpmana/

\section{UCZELNIA WYŻSZA JAKO FORMA KOMUNIKATYWNEJ PRZESTRZENI WSPÓŁZALEŻNEJ OSOBOWOŚCI}

Komunikacja jest postrzegana jako złożony proces, który organizuje przestrzeń społeczno-kulturową. Za pomocą procesu komunikacji społeczeństwo tworzy przestrzeń informacyjno-komunikacyjną, ustawiając granicę między komunikacjami i ludzkością. Analizie poddano różne podejścia naukowe psychologiczne i socjologiczne do pojęcia „przestrzeń komunikatywna”.

Przestrzeń komunikatywna jest rozpatrywana jako uwarunkowanie socjalizacji młodych pokoleń; jako całokształt warunków realizacji procesów komunikacji oraz komunikatywnych praktyk (komunikatywna kompetencja, komunikatywna kreatywność, zdolności komunikacyjnych itp).

Odmianą społeczno-komunikatywnej przestrzeni oświaty jest społecznokomunikatywna przestrzeń uczelni wyższej, która jest kształtowana sukcesyjnie w procesie socjalizacji jednostek ulega określonym zmianom pod wpływem instytucji społecznych rodziny, edukacji i wychowania, a także nieformalnych stosunków w bezpośrednim mikrootoczeniu; w określonym stopniu zależy od sprawności fizycznej i społecznopsychologicznych zdolności jednostki. Osób społeczność współzależne ma wiele represjonowane myśli, uczuć i ukrytych motywów, niskiej samooceny i wstydu. Ponadto komunikatywna przestrzeń zbudowana jest na zasadzie „trójkąta” S. Karpmana - to zjawisko, w którym istnieją relacje pomiędzy „prześladowcą” i „ofiarą”, między „ofiarą” i „,ratownikiem”. Jeśli ratownik i prześladowcą przestał komunikacji, gra się zakończyć w Codependency. Ponieważ zawód nauczyciela odnosi się do grupy "pomoc", "Zapisz", zjawisko Codependency przejawia się w rzeczywistości edukacyjnej szkolnictwa wyższego. Slowa kluczowe: komunikacja, przestrzeń, przestrzeń komunikacji, zleceń

\section{AN INSTITUTION OF HIGHER EDUCATION AS A FORM OF COMMUNICATIVE SPACE}

The concept of "communicative space" has been analyzed in the psychological and social aspects. An institution of higher education is regarded as a form of communicative space. Communication is considered as a complex process which organizes sociocultural space. With the help of processes of communication society creates informationcommunicative space setting the line between communications and humanity. Different scientific approaches in psychology and sociology to the concept of "communicative space" have been analyzed.

Communicative space is regarded as: a) the condition of socialization of young generations; b) the set of conditions for communicative processes; c) the totality of communicative practices (communicative competence, communicative creativity, communicative abilities, etc.).

The type of socio-communicative space of education in general is a sociocommunicative space of a higher educational institution which:

a) is formed by stages in the process of socialization of individuals;

b) undergoes some changes under the influence of social institutions of family, education and upbringing, and of informal relations in the direct microenvironment surroundings;

c) is to some extent dependent on the physical and social-psychological abilities of a person. 
The communication of co-dependent people contains many repressed thoughts, feelings, and ulterior motives, low self-rating and shame. Moreover, the communication area is built due to S.Karpman drama triangle where there is a relationship between a "persecutor" and "rescuer" as well as between a "victim" and "rescuer". If the rescuer and persecutor ceased the communication, the co-dependence game would stop.

Since, the profession of pedagogue regards to the group of "assistants", "rescuers", the co-dependence phenomenon also appears in the pedagogical reality of a higher educational establishment.

Keywords: communication, space, communicative space, dispositions.

DOI:10.7862/rz.2014.hss.7

Tekst złożono w redakcji: luty 2014

Przyjęto do druku: czerwiec 2014 